\title{
Bio-chemical imaging of phosphorus- related maize rhizosphere processes in the field
}

\author{
EVA OBURGER ${ }^{1}$, CHRISTINA HUMMEL ${ }^{1}$, NATALIYA \\ BILYERA $^{2}$, GABRIEL DAUDIN ${ }^{3}$, BAHAR RAZAVI ${ }^{2}$, \\ MICHAEL SANTANGELI ${ }^{1}$, SANDRA SPIELVOGEL ${ }^{2}$, \\ ISABELLE BERTRAND ${ }^{3}$, EVA LIPPOLD ${ }^{4}$, STEFFEN \\ SCHLUETER $^{4}$ AND DORIS VETTERLEIN ${ }^{4}$ \\ ${ }^{1}$ University of Natural Resources and Life Sciences \\ ${ }^{2}$ Christian-Albrechts-Universität zu Kiel \\ ${ }^{3}$ INRAE-IRD-Cirad-Supagro \\ ${ }^{4}$ Helmholtz Centre for Environmental Research - UFZ \\ Presenting Author: eva.oburger@boku.ac.at
}

Understanding phosphorus (P) dynamics in the soil-plant system provides the basis for reducing the dependency on external $\mathrm{P}$ fertilizer inputs and allows optimized and sustainable crop production. Plants use various strategies to overcome nutrient limitations including the development of different root morphologies as well as changes in root activity (e.g. proton and metabolite exudation) affecting rhizosphere properties, like phosphatase activity, and consequently also $\mathrm{P}$ solubility. To improve our understanding about the interaction of these rhizosphere processes, we set out to apply three non-destructive, 2D chemical imaging methods to visualize soil $\mathrm{pH}$ (planar optodes), phosphatase activity (zymography) and labile $\mathrm{P}$ and Mn fluxes (Diffusive Gradients in Thin films (DGT)) in the rhizosphere in situ. Zea mays L. root hair defective mutant $r$ th 3 and the corresponding wild-type (WT) were grown in a field trial in two repacked soil substrates (loam, sand) in Bad Lauchstädt, Germany. Twelve custom designed root windows $(60 \times 60 \mathrm{~cm})$ allowed to non-destructively access maize roots over the entire growth period. The three chemical imaging techniques were consecutively applied to the same regions of interest within a 5day sampling campaign to investigate the effect of root morphology and soil texture on the spatial distribution of phosphatase activity, soil $\mathrm{pH}$ and soluble $\mathrm{P}$ at maize growth stage $\mathrm{BBCH} 59$ (end of tassel emergence). Image analysis revealed a strong patchiness of all investigated parameters, however the average rhizosphere extent tended to be greater in sand than in loam. On average, $\mathrm{pH}$ decreased in the order bulk $>$ rhizosphere $>$ root, while phosphatase activity and Mn flux showed the opposite trend and no consistent patterns could be observed for $\mathrm{P}$ flux. Generally, substrate showed a stronger impact on investigated rhizosphere parameters than maize genotype.

The combined chemical imaging of different rhizosphere parameters (phosphatase activity, soil $\mathrm{pH}$ and nutrient $(\mathrm{P}, \mathrm{Mn}$ ) gradients) in situ demonstrated that despite high spatial heterogeneity, co-localization of individual $\mathrm{P}$ solubilizing processes in the rhizosphere jointly contribute to plant $\mathrm{P}$ nutrition. 